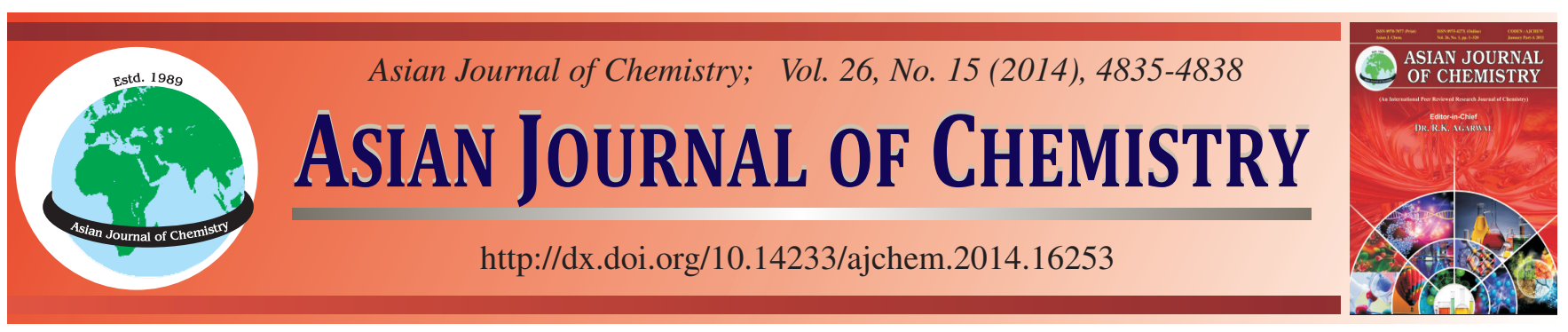

\title{
Supramolecular Dispersive Liquid-Liquid Microextraction and Determination of Copper by Flame Atomic Absorption Spectrometry
}

Tao Luo, Yingtang Li, Chang Liu and Mousheng Liu*

Faculty of Life Science and Technology, Kunming University of Science and Technology, Kunming 650504, R.P. China

*Corresponding author: Tel: +86 13888284022; E-mail: 1msh128@sina.com; 1t735458025@163.com

Received: 29 August 2013;

Accepted: 25 October 2013;

Published online: 16 July 2014;

AJC-15582

\begin{abstract}
A simple, safe, environmentally friendly, rapid and inexpensive method based on supramolecular dispersive liquid-liquid microextraction (SM-DLLME) was developed for the preconcentration and separation of copper in water samples prior to flame atomic absorption spectrometry analysis. The 1-(2-thiazolylazo)-naphthol was selected as chelating reagent to react with copper, and the supramolecular solvent which was proposed for dispersing and extracting solvent was made up of nonanoic acid, tetrahydrofuran and water. Some influential factors affecting the analytical performance were studied. Under the optimum conditions, the calibration graph was linear in the range of $10-800 \mu \mathrm{g} \mathrm{L}{ }^{-1}$, the limit of detection (LOD) was $0.3 \mu \mathrm{g} \mathrm{L}-1$ for copper, the relative standard deviations $(\mathrm{RSD}, \mathrm{n}=6)$ was $2.6 \%$, respectively. The satisfactory relative recoveries (93.5-101.5\%) were achieved after the determination of copper in water samples.
\end{abstract}

Keywords: Supramolecular dispersive liquid-liquid microextraction, Copper, 1-(2-Thiazolylazo)-naphthol.

\section{INTRODUCTION}

Currently, the pollution of environment by large amount of toxic elements has been tempestuously increased. Trace levels of heavy metals are widely distributed in environment due to human activities ${ }^{1-3}$. Besides, many reports which are directly bound up with heavy metal pollution have drawn much more attention. As an important bioelement and trace metal, copper plays a significant role in biological system ${ }^{4}$. It's a necessary micronutrient for human body. But it can cause detrimental effects when it exceeds a certain specified value ${ }^{5-8}$. Therefore, to keep it at trace level, the detection of copper is of significant importance.

Many methods for the determination of metals by atomic spectrometry techniques are commonly using a preconcentration step before their detection. Owing to the brief operation, low acquisition and high sample throughput, flame atomic absorption spectrometry (FAAS) has been a very attractive technique for conventional metal determinations ${ }^{9}$. But due to their low concentrations in aqueous sample, it is still very necessary to preconcentrate the trace metals prior to their determination.

Due to the low concentration and matrix interference of copper in samples, it's difficult to detect it directly, so preconcentration and separation techniques are in high demand. Even some traditional extraction methods like solid phase extraction $(\mathrm{SPE})^{10,11}$, liquid-liquid extraction (LLE) $)^{12-14}$ are widely used, they do have their inevitable drawbacks i.e., tedious and suffers from large consumption of toxic organic solvents. To conquer these shortcomings, different types of liquid phase microextraction (LPME) such as single drop microextraction (SDME) $)^{15,16}$, cloud point extraction $(\mathrm{CPE})^{17,18}$, dispersive liquid-liquid microextraction (DLLME) $)^{19,20}$ have been developed. In our work, a fast, simple, environmentally friendly and efficient extraction technique, supramolecular dispersive liquid-liquid microextraction (SM-DLLME) was employed to detect copper in water samples. This extraction technique was initially created by Watanabe and co-workers ${ }^{21}$ on the basis of micellar coacervates produced by increasing the tempertature of aqueous solutions of non-ionic micelles above a certain value. In comparison with traditional DLLME, SM-DLLME uses environmentally friendlier solvents and same as DLLME extraction time is very short due to the large surface area between analyte and extraction solvent.

In this paper, a supramolecular made up of nonanoic acid reverse micelles in tetrahydrofuran by addition of water. [1(2-Thiazolylazo)-2-naphthol], as the hydrophobic ligand, was reported as the chelate agent with trace metal ${ }^{22}$. So after the reaction of copper with 1-(2-thiazolylazo)-naphthol, the formation of a complex was injected into the supramolecular solvent we mentioned before, then analysis by flame atomic absorption spectrometry. According to our knowledge, using the 1-(2-thiazolylazo)-naphthol as chelating agent for supramolecular solvent-based microextraction of copper has not been reported before. Several parameters that may affect 
the extraction and determination procedures were also investigated.

\section{EXPERIMENTAL}

Stock standard solution $\left(1000 \mu \mathrm{g} \mathrm{mL} \mathrm{m}^{-1}\right)$ of copper was obtained from the National Institute of Standards (Beijing, China). Britton-Robinson buffer solution was composed of boric acid, acetic acid and phosphoric acid. Boric acid, acetic acid, phosphoric acid and tetrahydrofuran were analytical grade and purchased from Sigma (St. Louis, Mo., USA). 1(2-Thiazolylazo)-naphthol was analytical grade and purchased from Shanghai Chemical Reagent Co., (Shanghai, China). $\mathrm{NaOH}$ was analytical grade and purchased from Zhiyuan Chemical Reagent Co., (Tianjing, China). Purified water was obtained by Aike water purification system (Chengdu, China) and used throughout this work. All the reagents used in this study were analytical grade.

Flame atomic absorption spectrometer (Z-2000, Hitachi, Japan) was used for the determination of copper ion. Vortex oscillator (Shanghai, China) was used to mix the supramolecular solvent and follow-up study with copper and 1-(2thiazolylazo)-naphthol. The centrifuge with calibrated centrifugal tubes (Shanghai, China) was used to accelerate the phase separation process.

Preparation of supramolecular solvent: The supramolecular solvent was prepared by the following procedure. $2 \mathrm{~mL}$ of nonanoic acid, $10 \mathrm{~mL}$ of tetrahydrofuran were added in a $50 \mathrm{~mL}$ of plastic centrifuge tube, respectively, then dilute to $50 \mathrm{~mL}$ by distilled water. After this, the mixture was fiercely stirred by a vortex oscillator for $5 \mathrm{~min}$. Then the sufficient phase separation was finished by centrifugation at $4000 \mathrm{rpm}$ for $5 \mathrm{~min}$. Finally, the supramolecular solvent, which is less dense than water and then remains at the top, was withdrawn and transferred into a thermetically close storage glass vial and stored at $4{ }^{\circ} \mathrm{C}$.

Supramolecular dispersive liquid-liquid microextraction: Aliquots of $500 \mu \mathrm{L} 10 \mu \mathrm{g} \mathrm{mL}^{-1}$ of $\mathrm{Cu}$ standard solution, $1 \mathrm{~mL}$ pH 8 Britton-Robinson buffer solution, $1 \mathrm{~mL}$ of supramolecular solvent and $1 \mathrm{~mL} 100 \mu \mathrm{g} \mathrm{mL}^{-1} 1$-(2-thiazolylazo)naphthol solution as chelating agent were placed in a graduated centrifuge tube. Then the mixed solution was stirred by a vortex oscillator for $5 \mathrm{~min}$. Separation of the two phases was accelerated by centrifugation for $5 \mathrm{~min}$ at $4000 \mathrm{rpm}$. The aqueous phase was then removed using a syringe with a long needle. Then the supramolecular solvent phase was diluted with methanol solution containing $1 \mathrm{~mol} \mathrm{~L}^{-1} \mathrm{HNO}_{3}$ to $1 \mathrm{~mL}$ and determined by flame atomic absorption spectrometry (FAAS).

\section{RESULTS AND DISCUSSION}

In order to evaluate the optimum SM-DLLME conditions for the determination of copper in water samples, the effects of different parameters on the performance of the method were investigated.

Effect of 1-(2-thiazolylazo)-naphthol concentration: In this paper, 1-(2-thiazolylazo)-naphthol was selected as the chelating reagent to react with copper. In order to evaluate the chelating efficiency, different concentration of 1-(2-thiazolylazo)- naphthol in the range of $2-10 \mu \mathrm{g} \mathrm{mL}^{-1}$ were used. As shown in Fig. 1, when the concentration of 1-(2-thiazolylazo)-naphthol was up to $8 \mu \mathrm{g} \mathrm{mL}^{-1}$, the recovery of copper reached the peak. With the further increase of the concentration, the recovery did not show any obvious change. So a concentration of 10 $\mu \mathrm{g} \mathrm{mL} \mathrm{L}^{-1}$ 1-(2-thiazolylazo)-naphthol was chosen as the best concentration.

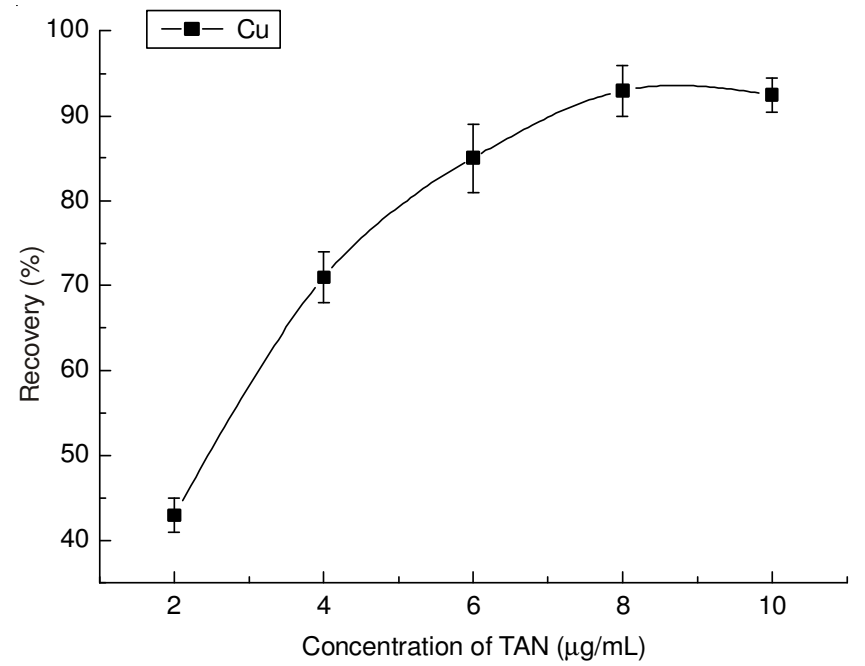

Fig. 1. Effect of 1-(2-thiazolylazo)-naphthol concentration. Experi-mental conditions: $500 \mu \mathrm{g} \mathrm{L}^{-1}$ of $\mathrm{Cu}, 1 \mathrm{~mL}$ supramolecular solvent and $\mathrm{pH}$ 8. Other experimental conditions are described under procedures

Effect of pH: The $\mathrm{pH}$ plays a very important role during the reaction ${ }^{23}$. For this reason, the effect of $\mathrm{pH}$ was investigated within the range of $\mathrm{pH} 2-10$. As we can see from Fig. 2, the recovery kept increasing with the rising of the $\mathrm{pH}$. When $\mathrm{pH}$ reached 8 , the recovery reached the peak. So $\mathrm{pH} 8$ was chosen for further study.

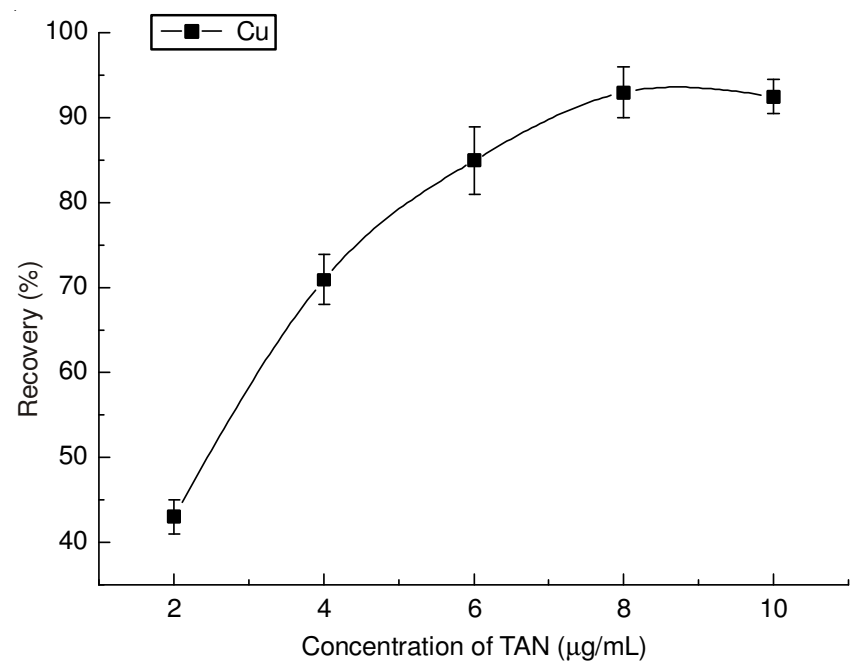

Fig. 2. Effect of $\mathrm{pH}$. Experimental conditions: $500 \mu \mathrm{g} \mathrm{L} \mathrm{L}^{-1}$ of copper, $10 \mu \mathrm{g}$ $\mathrm{mL}^{-1}$ of 1-(2-thiazolylazo)-naphthol and $1 \mathrm{~mL}$ of supramolecular solvent. Other experimental conditions are described under procedures

Effects of type and volume of supramolecular solvent: Three types of organic acid, octanoic acid, valeric acid and nonanoic acid were chosen as the potential supramolecular solvent. The results shown in Fig. 3, proved nonanoic acid 
was the best supramolecular solvent for the extraction of copper. The effect of concentration of nonanoic acid on extraction efficiency was also investigated. As shown in Fig. 4, the obtained outcome showed that $1 \mathrm{~mL}$ of the supramolecular solvent was chosen as the optimum volume for this study.

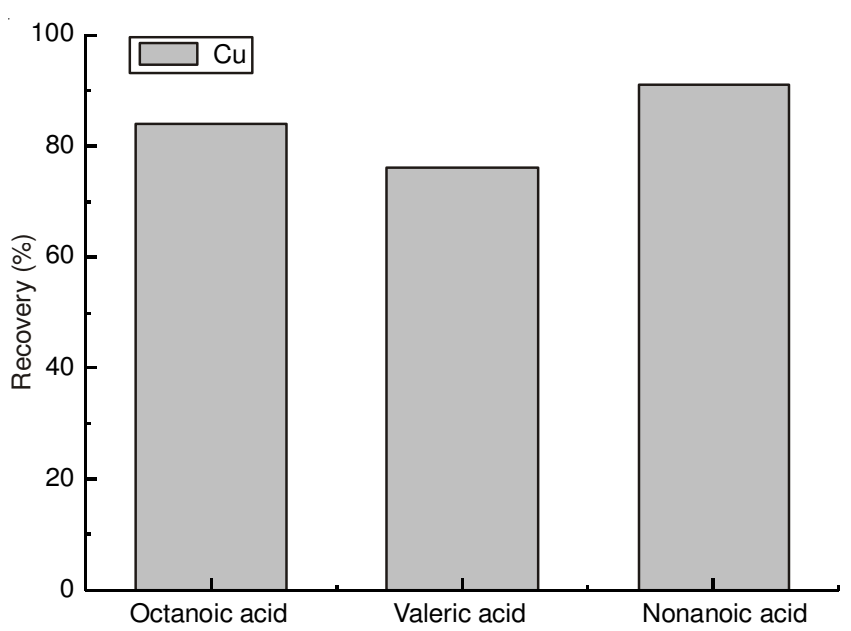

Fig. 3. Effect of type of supramolecular solvent. Experimental conditions: $500 \mu \mathrm{g} \mathrm{L}^{-1}$ of copper, $10 \mu \mathrm{g} \mathrm{mL} \mathrm{L}^{-1}$ of 1-(2-thiazolylazo)-naphthol and $\mathrm{pH}$ 8. Other experimental conditions are described under procedures

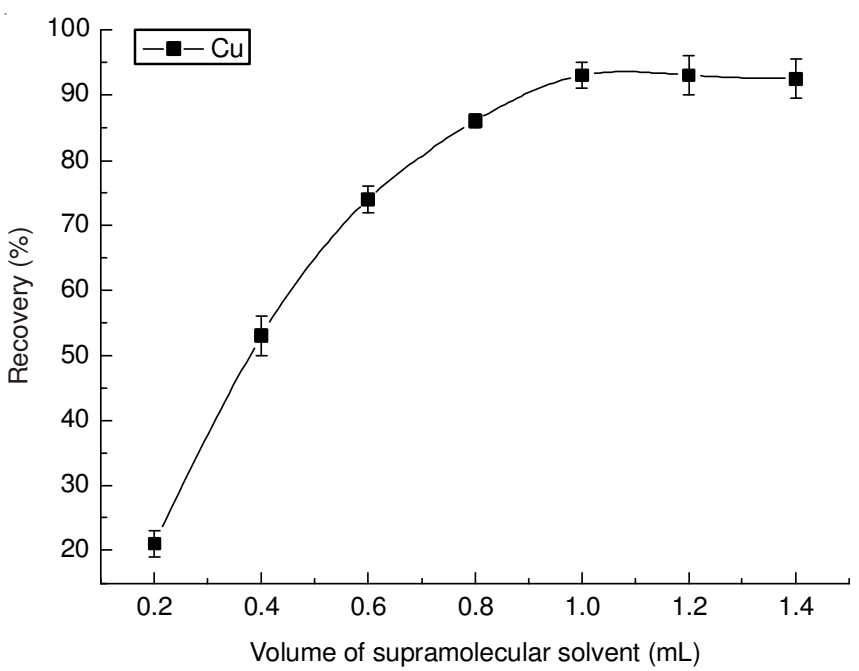

Fig. 4. Effect of volume of supramolecular solvent. Experimental conditions: $500 \mu \mathrm{g} \mathrm{L}^{-1}$ of copper, $10 \mu \mathrm{g} \mathrm{mL}^{-1}$ of 1-(2-thiazolylazo)naphthol and $\mathrm{pH}$ 8. Other experimental conditions are described under procedures

Effect of vortex time: Vortex process was used to accelerate the supramolecular solvent spontaneously formed into the bulk solution and mix the solution thoroughly. So the vortex time was investigated in the range of 1-7 min. Fig. 5 showed that the recovery of copper was increased by rising the vortex time up to 5 min. Thus, the optimal vortex time in this study is $5 \mathrm{~min}$.

Analytical features: Under the optimum conditions, the calibration graph was linear in the range of $10-800 \mu \mathrm{g} \mathrm{L}^{-1}$, the limit of detection (LOD) was $0.3 \mu \mathrm{g} \mathrm{L}^{-1}$ for copper and the relative standard deviations ( $\mathrm{RSD}, \mathrm{n}=6$ ) was $2.6 \%$ (Table- 1 ).

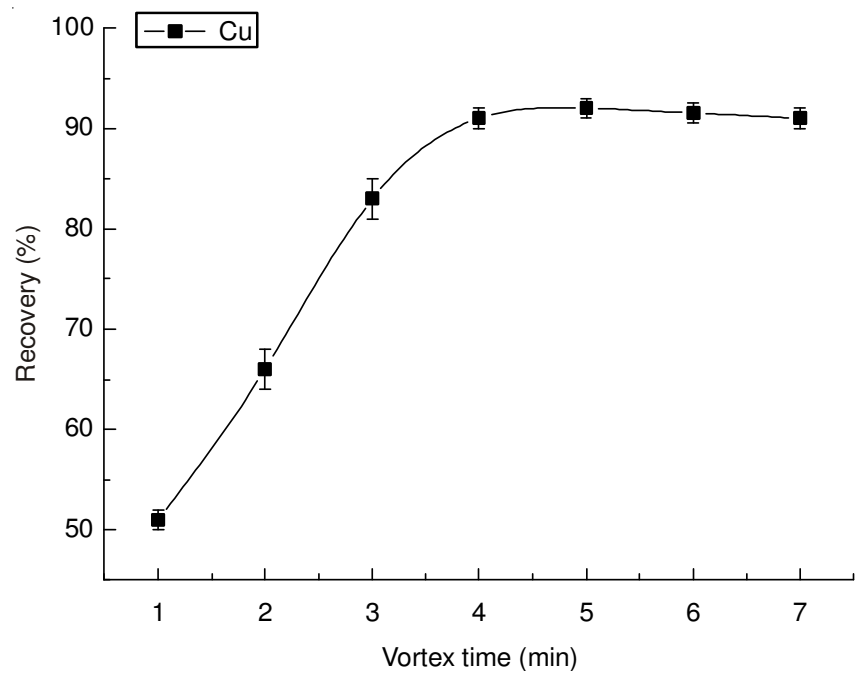

Fig. 5. Effect of vortex time. Experimental conditions: $500 \mu \mathrm{g} \mathrm{L^{-1 }}$ of $\mathrm{Cu}$, $10 \mu \mathrm{g} \mathrm{mL}^{-1}$ of 1-(2-thiazolylazo)-naphthol and $\mathrm{pH}$ 8. Other experimental conditions are described under procedures

\begin{tabular}{cccccc}
\multicolumn{7}{c}{ TABLE-1 } \\
PERFORMANCE CHARACTERISTICS \\
OF THE PROPOSED METHOD
\end{tabular}

Interference study: Generally, 1-(2-thiazolylazo)-naphthol is a very chelating agent for heavy metals. Therefore, the interferences from coexisting ions should be considered. To perform this study, $10 \mathrm{~mL}$ of solution containing $50 \mu \mathrm{g} \mathrm{L}^{-1}$ of $\mathrm{Cu}$ and different concentrations of other interfering ions were prepared for the extraction procedure. The tolerance limit would change with the change of the foreign ion concentration, but it is still less than $\pm 5 \%$. The results were shown in Table- 2 and proved that copper recoveries are almost quantitative in the presence of interfering metals in water samples.

TABLE-2

TOLERANCE LIMITS FOR IONS INTERFERING WITH THE DETERMINATION OF $50 \mu \mathrm{G} \mathrm{L}^{-1} \mathrm{Cu}(\mathrm{n}=6)$

\begin{tabular}{cc}
\hline Ions & Interfering ion to analyte ratio \\
\hline $\mathrm{K}^{+}, \mathrm{Na}^{+}, \mathrm{Ca}^{2+}, \mathrm{Mg}^{2+}$ & 2500 \\
$\mathrm{Al}^{++}, \mathrm{Fe}^{3+}, \mathrm{Mn}^{2+}$ & 1500 \\
$\mathrm{Hg}^{2+}, \mathrm{Cr}^{3+}$ & 1000 \\
$\mathrm{Cd}^{2+}, \mathrm{Ni}^{2+}, \mathrm{Co}^{2+}, \mathrm{Zn}^{2+}$ & 800 \\
$\mathrm{Cl}^{-}, \mathrm{HCO}_{3}, \mathrm{SO}_{4}^{2-}, \mathrm{PO}_{4}^{3-}$, & 2000 \\
$\mathrm{NO}_{3}^{-}, \mathrm{CH}_{3} \mathrm{COO}^{-}$ & 1500 \\
\hline
\end{tabular}

Analysis of real samples: In this study, tap water, river water and industrial wastewater were analyzed to evaluate the content of copper. The analytical results were presented in Table-3. According to the results in Table-3, the recoveries for the analytes were in the acceptable range of 93.5-101.5\%, so it demonstrated that the selected method could perfectly used for the analysis of water samples. 


\begin{tabular}{cccc}
\hline \multicolumn{5}{c}{ TABLE-3 } \\
\multicolumn{4}{c}{ DETERMINATION OF COPPER IN WATER SAMPLES } \\
\hline Samples & Added $\left(\mu \mathrm{g} \mathrm{L}^{-1}\right)$ & Found $\left(\mu \mathrm{g} \mathrm{L}^{-1}\right)$ & Recovery $(\%)$ \\
\hline \multirow{2}{*}{ Tap water } & 50 & 48.5 & 97.0 \\
& 100 & 96.8 & 96.8 \\
\hline \multirow{2}{*}{ River water } & - & 20.5 & - \\
& 50 & 65.9 & 93.5 \\
& 100 & 122.3 & 101.5 \\
\hline \multirow{2}{*}{ Industrial } & - & 40.6 & - \\
waste water & 50 & 88.6 & 97.8 \\
& 100 & 130.2 & 92.6 \\
\hline
\end{tabular}

\section{Conclusion}

In our study, a supramolecular solvent made up of nonanoic acid, tetrahydrofuran and water was proposed as a simple, safe, environmentally friendly, rapid and inexpensive method for the preconcentration and separation of heavy metals in water samples. The 1-(2-thiazolylazo)-naphthol used in this study was proved to be an efficient chelating reagent for copper. So the presented method can be satisfactorily employed for the determination of copper in water samples.

\section{ACKNOWLEDGEMENTS}

The work was greatly supported by the Analysis and Testing Foundation of Kunming University of Science and Technology (No. 20130430) and Yunnan Province Natural Science Foundation of China (2010ZC027).

\section{REFERENCES}

1. Q.X. Zhou, N. Zhao and G.H. Xie, J. Hazard. Mater., 189, 48 (2011)

2. L. Zhang, Z.H. Li, X.H. Du, R.J. Li and X.J. Chang, Spectrochim. Acta A, 86, 443 (2012)
3. A.N. Anthemidis and K.I.G. Ioannou, Talanta, 79, 86 (2009).

4. J. Škrlíková, V. Andruch, I.S. Balogh, L. Kocúrová, L. Nagy and Y. Bazel, Microchem. J., 99, 40 (2011).

5. Y.G. Ko, Y.J. Chun, C.H. Kim and U.S. Choi, J. Hazard. Mater., 194, 92 (2011).

6. F. Rashidi, R.S. Sarabi, Z. Ghasemi and A. Seif, Superlattices Microstruct., 48, 577 (2010).

7. M. Díaz-de Alba, M.D. Galindo-Riaño and M. García-Vargas, Talanta, 100, 432 (2012).

8. H. Shoaee, M. Roshdi, N. Khanlarzadeh and A. Beiraghi, Spectrochim. Acta A, 98, 70 (2012).

9. L.F.S. Caldas, D.M. Brum, C.E.R. de Paula and R.J. Cassella, Talanta, 110, 21 (2013)

10. D. Manivannan and V.M. Biju, Water Sci. Technol., 64, 803 (2011).

11. N. Pourreza, J. Zolgharnein, A.R. Kiasat and T. Dastyar, Talanta, 81, 773 (2010).

12. S. Kalidhasan, S. Sricharan, M. Ganesh and N. Rajesh, J. Chem. Eng. Data, 55, 5627 (2010).

13. E. Kaale, A. Van Schepdael, E. Roets and J. Hoogmartens, J. Pharm. Biomed. Anal., 30, 1331 (2002).

14. J.F. Liu, J.B. Chao and G.B. Jiang, Anal. Chim. Acta, 455, 93 (2002).

15. D. Verma, S.K. Verma and M.K. Deb, Talanta, 78, 270 (2009).

16. A. Jain and K.K. Verma, Anal. Chim. Acta, 706, 37 (2011).

17. H.C. Rezende, C.C. Nascentes and N.M.M. Coelho, Microchem. J., 97, 118 (2011).

18. H.I. Ulusoy, R. Gurkan and S. Ulusoy, Talanta, 88, 516 (2012).

19. M. Rezaee, Y. Yamini, A. Khanchi, M. Faraji and A. Saleh, J. Hazard. Mater., 178, 766 (2010).

20. F.S. Rojas, C.B. Ojeda and J.M.C. Pavon, Anal. Methods., 3, 1652 (2011).

21. H. Ishii, J. Miura and H. Watanabe, Bunseki Kagaku, 26, 252 (1977).

22. Z. Li, G. Yu, J. Song, Q. Wang, M. Liu and Y. Yang, Water Sci. Technol., 67, 247 (2012).

23. A.B. Tabrizi, J. Hazard. Mater., 183, 688 (2010). 